\title{
Preliminary Study of Factors Affecting the Training Performance in Property Management Companies
}

\author{
Tai-Ho Yang ${ }^{1 *}$, Chieh-Ming Wang ${ }^{1,2,3}$ \\ ${ }^{1}$ Department of Business Administration, Kun Shan University, Tainan, Taiwan \\ ${ }^{2}$ CEO of Guocheng Property Management Co., Ltd., Tainan, Taiwan \\ ${ }^{3}$ Executive Supervisor of Property Management Development Association, Tainan, Taiwan \\ *Corresponding author. Email: mkc@mail.ksu.edu.tw
}

\begin{abstract}
The present study aimed to construct a research framework to investigate the relationships among internal and external factors, learning motivation, and training performance among the property management companies' employees. The research participants were the employees of property management companies in Tainan area who had participated the Talent Quality-Management System (TTQS) training programs. The participants who had participated the TTQS training programs imply that the questionnaire response will has high validity and reliability. The present study tried to understand the effects of internal and external factors on learning motivation, the effects of internal and external factors on training performance, the effect of learning motivation on training performance, and the mediating effect of learning motivation toward the effects of internal and external factors on training performance.
\end{abstract}

Keywords: Internal and external factors, Learning motivation, Training performance

\section{INTRODUCTION}

The great change of the environment leads the world to make a rapid leap forward in a fast-changing direction. People live in this fiercely competitive and fast-changing era of knowledge economy. Knowledge is an element of individual survival, development power, and a source of competitive advantage, as well as the biggest capital for the survival and development of an enterprise.

In the era of knowledge economy, education and learning are the foundation of individual development. Faced with the ever-changing and obsolescence of technology and knowledge, traditional passive learning methods can no longer meet the rapid changing environment and individual learning needs in the workplace.

Taiwan is now facing the dual impact of aging and declining births, as well as global trade competition. The insufficient labour force indirectly affects the country's competitiveness, economic growth, high government burden, and the development of middle-aged and elderly-care service industries.

Therefore, investigating how to assist employees in the workplace to continuously learn new knowledge and skills is necessary to develop a suitable education and training model. Not only it can ensure the viability of employees in the workplace, but also increase the competitiveness of enterprises.

The present study intended to investigate the factors that affect personnel training in property management companies. The purpose of present study is to understand the relationship among environmental and background factors, learning motivation, participate willingness, and training performance.

\section{LITERATURE REVIEW}

The literature review is majorly concerned in training and education, learning motivation, internal and external factors, and property management.

\subsection{Training and Education}

Training is short-term, professional, and functional; education is a long-term, extensive, comprehensive, and developmental learning. Training is a formal procedure used by a company to assist employees in learning and to help their behaviours accomplish the company's goals [1]. Education refers to any process and method of developing individuals' values, required abilities, attitudes, and behaviours in the society in which they live [2]. For enterprises, the implementation of training and education is to fill the gap between business objectives and current human resources, as well as to minimize the loss due to insufficient staff capabilities. On the other hand, through training and education, employees' intelligence is improved, learning motivation is promoted, and job satisfaction is promoted. The comparison of training and education is shown in Table 1.

Basically, both the training and education, their purposes are to enhance or improve the competency of the learners. The competency includes three aspects, namely knowledge, attitude, and skills. The learners combine these abilities to 
complete the task or activity. Figure 1 shows the competency model [3].

Table 1 The Comparison of Training and Education

\begin{tabular}{|c|l|l|}
\hline Items & \multicolumn{1}{|c|}{ Training } & \multicolumn{1}{c|}{ Education } \\
\hline Objective & Gain professional skills at work & Gain general knowledge \\
\hline Orientation & Job-based expertise and skills & Personal development-oriented knowledge \\
\hline Range & Narrow & Wide \\
\hline Function & Development talent & Development human resource \\
\hline Apply & Needed immediately & Future needs \\
\hline Application & Practical use & Concept inspiration \\
\hline
\end{tabular}

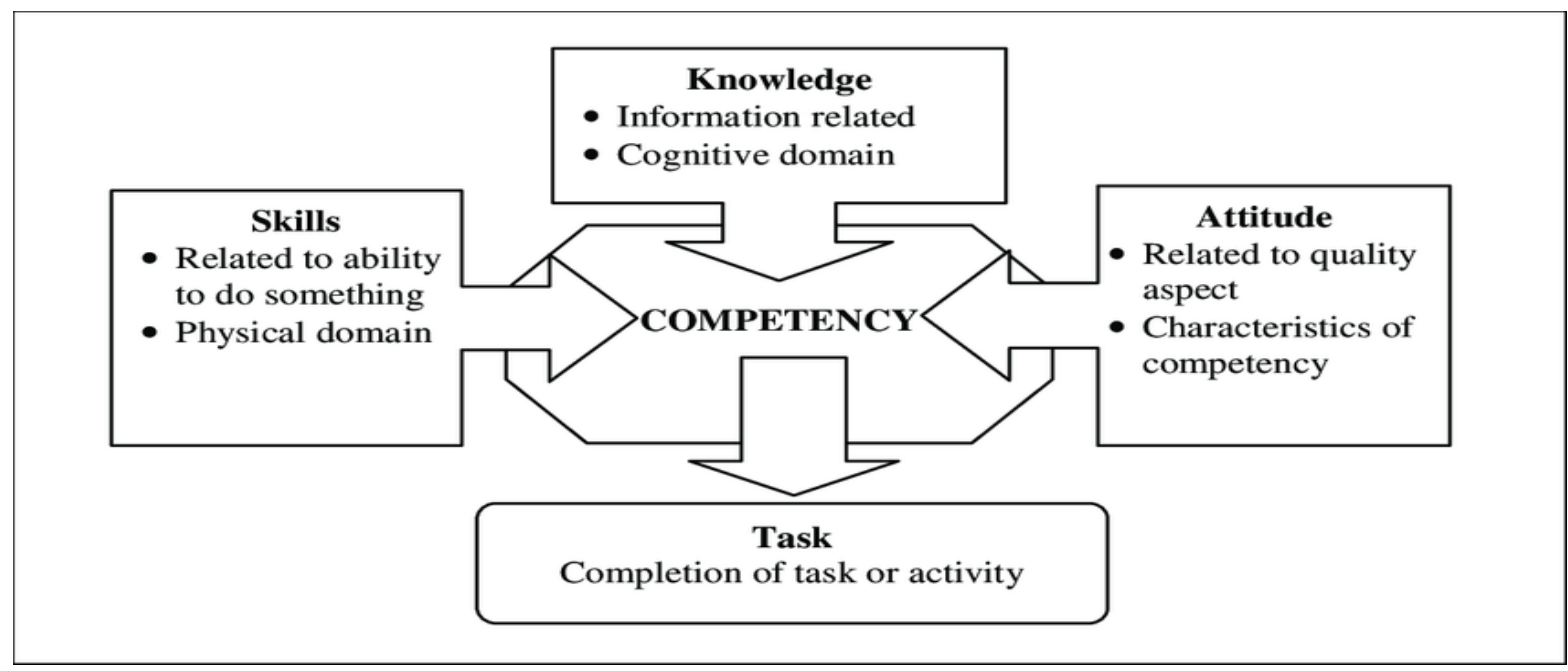

Figure 1 Competency Model [3]

\subsection{Learning Motivation}

Learning motivation is a kind of mental journey that leads learners to participate in learning activities, maintain learning activities, and move towards the established learning goals [4][5]. Stipek [6] regarded that learning motivation is the achievement motivation of students in learning, which is a psychological need for individuals to pursue their success, and one of the important factors that affect learning performance.

The theory of learning motivation majorly includes four categories: Behaviourism, Cognitivism, Social Learning Orientation, and Humanism. (1) Behaviourism: The idea of behavioural motivation theory is that people's actions are driven by driving forces, which are caused by physiological needs. (2) Cognitivism: Cognitive motivation theory considers that learning motivation is an intermediary process between the environment and individual behaviour [7]. (3) Social Learning Orientation: It integrates the viewpoints of behavioural and cognitive orientation, and takes into consideration the influencing factors such as the results and effects of behavioural orientation and the personal beliefs and expectations of cognitive orientation. (4) Humanism: Humanistic motivation theory treats education as a process of developing humans' intrinsic potential and learning motivation as an intrinsic driving force for human growth [7].

\subsection{Internal and External Factors}

There are many factors that influence the learners' learning motivation and training performance. In summary, those factors can be divided into two categories: internal and external factors. There are also many internal and external factors. The present study only investigated the most major factors: environmental, organizational, and personal factors.

\subsubsection{Environmental Factors}

Naisbitt and Aburdene [8] pointed out that the global economy is one of the major trends of the 21 st century, and will face accelerated changes that have never been seen before. The most amazing thing is the rapid progress of the world towards a single economy.

One of the important factors affecting adult learning is the economic structure and the constant changes in the economy. The learning needs of adults also change, especially when people understand the global 
interdependence, the development of the service industry, and changes in the composition of the working population [9].

Darkenwald and Scanlan [10] divided the factors of adult learning into four classifications: (1) Situational factors: Cost, lack of time, inconvenience of transportation, lack of care for children, remote location, etc. (2) School factors: Lack of attractive or appropriate curriculum, inconvenience caused by school policies and measures. (3) Informational factors: Insufficient publicity to allow individuals to search for or use the effective information. (4) Psychological factors: Including beliefs, values, attitudes, and cognitions held by individuals.

\subsubsection{Organizational Factors}

To increase competitiveness, organizations must provide training opportunities to strengthen or expand the capabilities of employees. Most of the training content is related to the functions of the job. Through training, the function gap is shortened and the work efficiency is improved.

Selvarajan and Cardy [11] regarded that from a management perspective, competency is a combination of resources and capabilities. Jain and Martindale [12] indicated that continuous learning is important not only for the working teams, but also for short-term and long-term success for individuals and organizations. Jain and Martindale [12] defined perpetual learning as a continuous process of learning and developing in an organizational environment which can also be perceived as a subset of the life-time learning process. Knowles [13] pointed out that perpetual learning is not only limited to the learning process in schools, but also refers to the process of learning in a lifetime. Knowles [14] also proposed an adult learning model, which emphasizes the distinction between adult and non-adult learners in four aspects, which are independence, experience, preparation, and learning direction.

\subsubsection{Personal Factors}

Chang [15] indicated that different personal factors will cause different problems in learning. The personal factors are summarized into five items such as gender, age, marital status, financial burden, and position as described below: (1) Gender is one of the factors affecting learning disabilities. Females' obstacles mostly come from family factors, and the participation rate in learning is lower than that of males. (2) Age: Married people with different ages have significant differences in learning and family conflicts. Learners between the age of 31 to 40 have more conflicting roles than those under the age of 30. (3) Marital status: Most of the obstacles of married people come from family factors, married learners with children aged 3-5 years have higher levels of learning and family conflict than married adults with children aged 13-18 years. (4) Financial burden: With a proper career and a better economic situation, they can easily complete their studies step by step; Otherwise, it is easier to terminate the learning through anxiety and frustration. (5) Position: Conflicts in the roles of grassroots and middle-level employees are higher than those of highlevel positions, and the higher the socio-economic status is, the greater the learning pressure will be.

\subsection{Property Management Companies}

\subsubsection{Definition of Property Management}

Property refers to a general term for different types of real estate, including land or building types. Property management is the management and maintenance of properties conducted by professional human resources in the working community and regular communication with paying users. The purpose of property management is to make (screening, hiring, and training) highly qualified personnel to provide management services, for paying users to enjoy a safe, healthy, comfortable, clean, environmentally-friendly, convenient, and functional living and working space.

\subsubsection{The Scope of Property Management}

The service scope of property management can be divided into investment management and building management. (1) Investment management: The purpose of investment management is to create or increase the additional use, benefit, and value of the property, and to create the largest real-estate investment return for the owner. (2) Building management: The purpose of building management is to supervise and control the physical facilities of the property to maintain effective operation, to allow users to have a high-quality building environment, and to maintain and retain the highest building value for the interest of the owner.

\subsubsection{Property Management Overview in Tainan}

Due to the complexity of commercial sites, it is necessary to have full-time professionals to manage the entry and exit of relevant sites, and to address public property, danger prevention, property management, and other related property management matters. There are more than one thousand property management sites with more than 50,000 employees.

\section{RESEARCH METHOD}

\subsection{Research Structure}

The research framework of the present study includes four facets: internal and external factors; learning motivation; willingness to participate; and training performance, which are shown in Figure 2. 


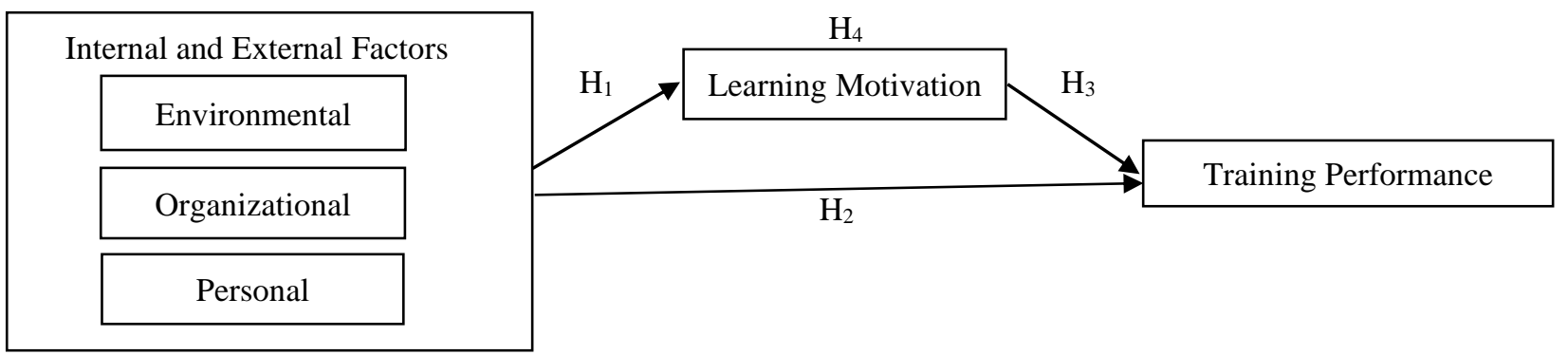

Figure 2 Research Framework of Present Study

\subsection{Research Hypothesis}

According to the research framework in Figure 1, the research hypotheses of present study are described as follows:

Hypothesis 1: Internal and external factors significantly affect the learning motivation.

$\mathrm{H}_{1-1}$ : Environmental factors significantly affect the learning motivation.

$\mathrm{H}_{1-2}$ : Organizational factors significantly affect the learning motivation.

$\mathrm{H}_{1-3}$ : Personal factors significantly affect the learning motivation.

Hypothesis 2: Internal and external factors significantly affect the training performance.

$\mathrm{H}_{2-1}$ : Environmental factors significantly affect the training performance.

$\mathrm{H}_{2-2}$ : Organizational factors significantly affect the training performance.

$\mathrm{H}_{2-3}$ : Personal factors significantly affect the training performance.

Hypothesis 3: Learning motivation significantly affects the training performance.

Hypothesis 4: Learning motivation significantly mediates the effect of internal and external factors on training performance.

$\mathrm{H}_{4-1}$ : Learning motivation significantly mediates the effect of environmental factors on training performance.

$\mathrm{H}_{4-2}$ : Learning motivation significantly mediates the effect of organizational factors on training performance.

$\mathrm{H}_{4-3}$ : Learning motivation significantly mediates the effect of personal factors on training performance.

\subsection{Research Investigation}

The research investigation includes two parts. The first part is the questionnaire which will be sent to the employees of the property management companies in Tainan area. The second part is in-depth interview to the owners of the property management companies in Tainan area.

\subsection{Research Participants}

The research participants also include two parts. The first part is the employees of property management companies in Tainan area who had participated the Talent QualityManagement System (TTQS) training programs. The TTQS training and education programs is certified by the Ministry of Labour, that have a fairly strict certification process. The second part is the owners of the property management companies in Tainan area.

\section{EXPECTED RESULTS (CONCLUSIONS)}

The present study expects to obtain the following results:

(1). The effects of internal and external factors on learning motivation.

(2). The effect of learning motivation on training performance.

(3). The effects of internal and external factors on training performance.

(4). The mediating effect of learning motivation toward the effects of internal and external factors on training performance.

\section{REFERENCES}

[1] W. McGehee, P.W. Thayer, Training in Business and Industry, New York: Wiley, 1961.

[2] C.-X. Yang, A Dictionary of Technical Vocational Education, Sanmin, Taipei, (in Chinese) 1984.

[3] United Nations Industrial Development Organization. UNIDO Competencies: Strengthening Organizational Core Values and Managerial Capabilities. Vienna, Austria: UNIDO, 2002.

[4] P.D. Macintyre, R.A. Rebecca, Action control, motivated strategies, and integrative motivation as predictors of language learning affect and the intention to continue learning French. System, 40(4) (2012) 533543. 
[5] P.R. Pintrich, D.A.F. Smith, T. Garcia, W.J. McKeachie, Reliability and predictive validity of the motivated strategies for learning questionnaire (MSLQ). Educational and Psychological Measurement, 53(3) (1993) 801-813.

[6] D. Stipek, Effects of different instructional approaches on young children's achievement and motivation. Child Development, 66(1) (1995) 209-223.

[7] C.-X. Chang, Educational Psychology: Theory and Practice of the Three Orientations (3rd Edition), Donghua, Taipei, (in Chinese) 2000.

[8] J. Naisbitt, P. Aburdene, Megatrends 2000. New York: William \& Morrow, 1990.

[9] S.B. Merriam, R.S. Caffarella, Learning in Adulthood: A Comprehensive Guide. San Francisco: Jossey-Bass Publishers, 1999.

[10] G.G. Darkenwald, C.S. Scanlan, Identifying deterrents to participation in continuing education. Adult Education Quarterly, 34(3) (1984) 155-66.

[11] T.T. Selvarajan, R.L. Cardy, Competencies: Alternative frameworks for competitive advantage. Business Horizon, (49) (2006) 235-245.

[12] S. Jain, T. Martindale. Facilitating continuous learning: A review of research and practice of individual learning capabilities and organizational learning environments., 2012, Retrieved from http://www.aect.org/pdf/proceedings12/2012i/12_09.pd f.

[13] M.S. Knowles, The Modern Practice of Adult Education: From Pedagogy to Andragogy. Englewood Cliffs: Cambridge Books, 1980.

[14] M.S. Knowles, Andragogy in Action: Applying Modern Principles of Adult Education. San Francisco, Jossey-Bass, 1984.

[15] S.-M. Chang, Study on Learning Disabilities and Coping Strategies of Part-time Graduate Students, unpublish master thesis of National Chung Cheng University, Taiwan, (in Chinese) 2002. 